\title{
TAX DIMENSION OF THE STAFF WORKING IN PRIVATE HEALTH ORGANIZATIONS
}

DOI: 10.17261/Pressacademia.2020.1253

PAP- V.11-2020(25)-p.127-131

Burcu Haci ${ }^{1}$, Suat Teker ${ }^{2}$

${ }^{1}$ Isil University, School of Business, Istanbul, Turkey. burcusenvardar@gmail.com, ORCID: 0000-0003-3559-6142

${ }^{2}$ Isik University, School of Business, Istanbul, Turkey. suat.teker@isikun.edu.tr , ORCID: 0000-0002-7981-3121

To cite this document

Haci, B., Teker, S., (2020). Tax dimension of the staff working in private health organizations. PressAcademia Procedia (PAP), V.11, p.127-131 Permemant link to this document: http://doi.org/10.17261/Pressacademia.2020.1253

Copyright: Published by PressAcademia and limited licenced re-use rights only.

\section{ABSTRACT}

Purpose- It is to raise awareness of the physicians who take part in private health institutions by establishing self-employment obligations regarding their tax benefits and employee rights. As of our subject, the wages of the personnel working in private health ins titutions were analyzed by comparing the earnings, which are considered as wages in terms of the Turkish Tax System, and the self-employed wages.

Methodology- In the research model, the earnings of doctors working in private health institutions working in line with their expertise established on self-employment are discussed.

Findings- It has been determined that physicians who perform their profession as self-employed in the private health institution are advantageous in terms of tax compared to physicians who perform their profession for a fee.

Conclusion- According to the physician who performs her profession with a self-employed person in a private health institution, it is determined that is advantageous in terms of tax but is disadvantageous by labor law.

Keywords: Taxation of wages, taxation of income of independent personnel, income tax, source deduction method JEL Codes: M40, M41, M48

\section{ÖZEL SAĞLIK KURUMLARINDA ÇALIŞAN PERSONELIN VERGISEL BOYUTU}

\section{ÖZET}

Amaç- Özel Sağlık Kurumlarında serbest meslek mükellefiyeti tesis ettirilerek görev alan hekimlerin, elde ettikleri kazançların vergisel avantajları ve çalışan haklarına ilişkin kayıplarına yönelik farkındalık oluşturmaktır. Konumuz itibarıyla özel sağlık kurumlarında çalışan personelin elde edilen ücretlerin Türk Vergi Sistemi açısından ücret sayılan kazanç ile serbest meslek elde edilen ücretlerin karşılaştırmalarıyla incelenmiştir.

Yöntem- Araştırma modelinde, serbest meslek mükellefiyeti tesis ettirilen uzmanlıkları doğrultusunda görev alan özel sağlık kurumlarında çalışan doktorların elde ettikleri kazançları ele alınmıştır.

Bulgular- Özel sağlık kurumunda serbest meslek olarak mesleklerini icra eden hekimlerin ücretli olarak mesleklerini icra eden hekimlere ile karşılaştırıldığında vergisel yönden avantajı olduğu tespit edilmiştir.

Sonuç- Özel sağlık kurumunda serbest meslek erbabı ile ücretli olarak mesleğini icra eden hekime göre, vergisel yönden avantajlı olduğu ancak iş hukuku tarafından dezavantajı olduğu tespit edilmiştir.

Anahtar Kelimeler: Ücretlerin vergilendirilmesi, bağımsız çalışan personel gelirlerinin vergilendirilmesi, gelir vergisi, kaynakta kesinti yöntemi JEL Kodları: M40, M41, M48 


\section{Gíriş}

Özel sağlık kurumlarında çalışan doktorların elde ettikleri ücretlerin mahiyeti itibarıyla özel sağlık kurumu işleten gerçek veya tüzel kişiler ile doktorlar arasında düzenlenen anlaşmalar baz alınarak,

Doktorların, uzmanlıkları doğrultusunda mesleklerini icra etmek üzere kiralamış oldukları ofis ile bir özel sağlık kurumunda kendi mesleki bilgisine veya ihtisasına dayanan ve ticari mahiyette olmayan işlerin özel sağlık kurumuna bağlı olmaksızın kendi sorumlulukları altında şahsına ve hesabına yapılması durumunda söz konusu mesleki faaliyetlerinden doğan alacakları için hizmet verdiği hastalara serbest meslek makbuzu düzenlemeleri halinde elde ettikleri gelirlerin serbest meslek kazancı,

Özel sağlık kurumu veya kamu hastaneleri ile doktor arasında iş sözleşmesi düzenlenmesi durumunda ise iş yerine tabi ve belirli bir iş yerine bağlı olarak onun istek ve yönetmelikleri dahilinde çalışıması halinde ise elde edilen kazancın ücret olarak tanımlanmaktadır.

Sağlık Bakanlığının yayımlamış olduğu 2016 istatistik verilerine göre sağlık hizmetinin \%37'si özel sağlık sektöründen karşılanmakta olup, özel sağlık kesiminde hastanenin kurallarına ve yöneticilerin talimatlarına göre personel-işçi durumuna geldiği görülmektedir.

Özel sağlık kurumlarında çalışan hekimlerin ne şekilde vergilendirileceği ve elde edilen gelirin hangi gelir unsuru kapsamına gireceği, günümüzde karmaşık bir hale gelmekte olup, sağlık kurumunun yapısı ve çalışma koşulları esas alındığında, özel sağlık hastane si ile hastanede çalışan personelin arasındaki işçi-işveren bağlantısı mevcut olması durumunda ücret geliri olup özel sağ Iık kurumu ile kurumda çalışan personelin hizmetleri karşılığı doktorlar tarafından işletmeye serbest meslek makbuzu düzenlenmesi halinde ise serbest meslek kazancına göre vergilendirilmesi gerekmektedir. Özel Sağlık Kurumlarında serbest meslek mükellefiyeti tesis ettirilerek görev alan hekimlerin, elde ettikleri kazançların vergisel avantajları ve çalışan haklarına ilişkin kayıplarına yönelik farkındalık oluşturmaktır.

Bu çalışmada özel sağlık kurumlarında çalışan personelin elde edilen ücretlerin Türk Vergi Sistemi açısından ücret sayılan kazançile serbest meslek elde edilen ücretlerin karşılaştırmalarıyla incelenmiştir. Bu bağlamda, söz konusu doktorların elde edilen kazançların mahiyeti ve vergilendirilmesinde uygulanan yöntemler izah edilecek olup, elde edilen kazanç türlerine göre uygulamalara yer verilerek karşıla ştırmalar yapılacak, tenkit ve önerilerde bulunulacaktır.

\section{LITERATÜR INNCELEMESI}

Vergi, kamusal ihtiyaçlarını karşılamak maksadıyla tüzel ve gerçek kişilerden maddi olarak karşılığına vergi denilmektedir. Gelir ve Kazanç üzerinden alınan vergiler Kişi veya kuruluşların çeşitli işlemlerden elde ettikleri gelirleri üzerinden gelir vergisi kanunun da belirlenen oranlarda vergi alınır. Kanuni olarak Anayasanın 73. Maddesine göre, Millet, kamu giderlerini karşılanması amacıyla, ekonomi gücüne göre vergi ödemekle sorumludur. Vergi gibi mali sorumluluklar sadece kanun ile hüküm edilir, kaldırılır veya değiştirilir. (Akif, 1998) Dolaylı vergiler, direkt olarak vergi ödeyicisi ile vergi yükümlüsü aynı noktada buluşan vergilerdir. Vergi mükellefi olan herkes, elde edilen gelir düzeyine göre vergisini öder. Dolaylı vergilerde vergi yükümlüsüne düşen vergi tutarını başka bir vergi yükümlüsüne yansıtma olanağı bulunmamaktadır. Dolaysız vergilerin en iyi örnekleri ve bu çalışmanın da konu olan gelir ve kurumlar vergisidir. Dolaysız vergilerde vergi ta şıyan da vergi mükellefi de aynı kişidir.

Ücret, İş Kanunu'nun 32. maddesinde "Bir kimseye bir iş karşılığında işveren veya üçüncü kişiler tarafından sağlanan ve para ile ödenen tutardır" hükmüne yer verilmektedir. 193 sayılı Gelir Kanunu'nun 61. Maddesinde de ücretin tanıma yer verilmiş olup ücretin tanıma yer verilmiş olup hangi ad ile yapılmış olursa olsun ücretin mahiyetini değiştirilmeyeceği hüküm altına alınmıştır. Ücreti üç uns ura bağlanmış olup işverene tabi, belirli bir iş yerine bağı olarak çalışma ve bunun karşıı̆ında para veya temsil edilen menfaatler olarak tanımlanmıştır. Gelir vergisi açısından personelin elde edilen gelirin ücret sayılabilmesi için üç unsuru barındırması gerekmektedir. Bu üç unsurun ikisini veya bir koşulunun sağlanmaması halinde ücret gelirinden bahsedilmesi mümkün bulunmamaktadır. Ücret net tutar üzerinden, işveren tarafından yapılan para veya para ile temsil edilen menfaatlerin toplamından vergiye tabii olmayan kısaca istisna tutarların düşüldükten sonra kalan tutardır. İşveren tarafından personelin elde etmiş olduğu ücret üzerinden mevcut ise söz konusu tutardan istisna ve muafiyet tutarları üzerinden kesinti yapılarak kalan tutara isabet eden vergiyi hesaplayıp, ilgili ayda vergi dairesine sorumlu sıfatıyla beyan edip, ödemek zorundalardır.

Ülkemize iş güvencesi 1936 yılından günümüze kadar çalışma mevzuatının en duyarlı konularından biridir. İş güvencesi, işverenin fesih hakkında yasa ve sözleşme ile yapılan bütün sınırlamaları ve feshin sonuçları hafiften önlemleri kapsamak tadır. (Koç \& Kurt, 2007) Kurumdaki işçi ve işveren arasındaki bağlantı, işe alma süreci başlar ve işten ayrılma ya da çıkarılmasıyla sona erer. İşverenin iş sözleşmesini sona erdirmesinde birçok neden olabilmektedir.

İşçi iş sözleşmesinin sona ermesi durumunda haklarını alabilmesi için işçin haklı fesih ya da işverenin iş akdine son vermesi gerekmektedir.

İş̧in haklı neden feshi veya işveren tarafından işçinin çıkarılması halinde işçinin işverenden alacağı haklar aşağıdaki gibid ir.

- Ihbar Tazminatı

- Kıdem Tazminatı

- Kullanılmayan yıllık izin ücretleri

- $\quad$ Iş akdinin bitiş gününe kadar kazanılmış maaş

- Fazla mesai ücretleri

- İşsizlik ödeneği (İş-Kur tarafından belirli şartları sağlanması halinde)

- İşe iade davası

193 sayılı Gelir Vergisi Kanunu'nun birinci maddesinde gerçek kişilerin elde etmiş oldukları kazançları üzerinden vergi ödemek ile hükümlü oldukları belirtilmiştir. Söz konusu kazanç gerçek kişinin bir hesap dönemi içerisinde elde edilen kazanç ve iratların safi tutar olarak 
adlandırılmaktadır. Anılan Kanunu' nun 65. maddesinde her türlü serbest meslek faaliyetlerinden doğan kazançların serbest meslek kazancı olduğu belirtilmiş olup ve serbest meslek faaliyeti; sermayeden ziyade şahsi mesaiye, ilmi ve mesleki bilgiye veya ihtisasa dayanan ve ticari mahiyette olmayan işlerin işverene tabi olmaksızın, kendi sorumlulukları altında yapılması olarak tanımlanmıştır. (Türkay, 2016)

Gelir Vergisi Kanunu'nun 67. Maddesinde, serbest meslek kazancı ilgili hesap döneminde kendi bilgi ve ihtisasları doğrultusunda alacakları karşılığında para veya para ile temsil edilen menfaatlerden ilgili hesap dönemin faaliyete ilgili olması şartıyla giderlerin indirildikten sonra kalan fark olarak belirtilmiştir.

Serbest meslek kazancı, serbest meslek kazancı defteri ile tespit edilmektedir. Söz konusu defterin soluna giderler ve amortismana tabii iktisadi kıymetlerin amortisman tutarları, defterin sağ tarafına ise hasılatın konusu olan ayın ve para ile sağlanan menfaatlerin toplamı yer almaktadır. GVK'nın 94. maddesinin birinci fıkrasında belirtilen, kamu idare ve müesseseleri, iktisadi kamu müessesleri, sair kurumlar, ticaret şirketleri, iş ortaklıkları, vakıflar, dernekler ve bu vakıf ile derneklerin iktisadi işletmeleri, yatırım fonu yönetenler, g erçek gelirlerini beyan etmeye mecbur olan ticaret ve serbest meslek erbapları, zirai kazançlarını bilanço veya zirai işletme hesabı esasına göre tespit eden çiftçil erin maddede sayılan ödemeleri nakden veya hesaben yaptıkları sırada avans ödemeleri dahil olmak üzere istihkak sahiplerinin gelir vergilerine mahsuben kesinti yapmaya mecbur oldukları hüküm altına alınmıştır.Serbest meslek erbaplarına yapılan ödemelerin \%20 oranında vergi kesintisi yapılması gerekmektedir.

Serbest meslek faaliyetlerini icra eden gerçek kişilere yapılan ödemeler sırasında yukarıdaki oranlarda vergi tevkifatı yapılmakta olup, söz konusu tevkifat tutarlarının yıllık beyanname hesaplanan vergiden fazla olması halinde, serbest meslek erbabının bağı olduğu vergi dairesi tarafından vergi sorumlusuna yazı ile bildirilir ve vergi sorumlusu tebliğ tarihinden bir yıl içinde vergi sorumlusuna iade edilir.Serbest meslek erbabı bir takvim yılı içerisinde elde edilen gelirlere ilişkin yıllık beyannamesini takip eden Mart ayının 1 ile $25^{\prime}$ inci günü akşamına kadar bağ olduğu vergi dairesine beyan etmek ile yükümlüdürler. Söz konusu vergi tutarlarının Mart ve Temmuz ayında iki eşit taksit halinde ödemeleri zorunludur.

Türkiye'de 1980'li yılların başından itibaren başlayan sağlık sektörünün özelleştirilmesi günümüzde hızlı artış göstermektedir. İster kişi ücretten isterse serbest meslek kazancından oluşsun her ikisi de emeğe dayalı gelirin ilkesidir. Ancak bazı durumlar her iki kazanç türü birbirine karışabilmektedir. Serbestmeslek kazancıuzmanlığı doğrultusunda belli bir kurum bağı olmaksızın, işçi-işverenbağı olmaksızın kendi adına çalışması sonucu elde edilen gelir türüdür. Ücret ise işçi -işveren ilişkisine dayalı, işverenin talimatları doğrultusunda elde edilen gelir türüdür.

İşverene tabi olunup - olunmadığının tespiti epeyce süregelen tartışmalı bir konu olmuştur. Maliye Bakanlığı 34 seri numaralı Gelir Vergisi tebliğinde bu konuya açıklık getirilmiş kuruma ve sürekli bir kadroya bağlı olmadan ifa ettiği faaliyetlerden elde edilen gelirlerin ücret olarak değerlendirilemeyeceği, bir kuruma anlaşma ile uzmanlıkları ifa etmesi halinde ise ücret sayılacağı yönünde karar verilmiştir.

Bağ Iı olmadan bağımsız olarak mesleğini icra etmesini gerekmektedir. Ücret geliri elde eden bir personel için bağımsız bir şe kilde kurumda faaliyet göstermesi söz konusu olamaz. Çünkü bu kişiler kurumun bir parçası olarak kabul edilir ve kurumun bordrosunda gösterilmek üzere kaynakta kesinti yapılmak suretiyle vergilendirilir. Serbest meslek erbabı ise vergi sorumlusu olarak defter tutma, vergilerini yıllık beyanname verme, serbest meslek makbuz düzenlenmesi, katma değer vergisi ve geçici vergi yükümlüdürler.

Gelir Vergisi Kanunu'na göre gerçek ücretin vergilendirilmesinde geçerli olan tüm şartlar özel sağlık hastanelerde görev alan hekimlerin içinde geçerli olacaktır. Burada geçerli olan özel sağlık hastanelerde gelir elde edilen hekim artan oranlı vergi tarifesine göre tevkif suretiyle vergilendirilmektedir. 16.02.2009 tarihinde 40 No'lu Vergi Usul Kanunu'nun sirkülerinde özel sağlık kurumlarında görev alan doktorların gelirlerin mahiyeti belirlenmiş, doktorların işe başlama tebliğ, tebliğ üzerine düzenlenen yoklama fişi, mevcut ise kira sözleşmesi, özel sağlık kurumlarını işleten gerçek veya tüzel kişilerle doktorların arasında düzenlenen anlaşmalar dikkate alınarak, Kurum ile doktor arasında iş anlaşması düzenlenmesi, kuruma tabi ve kurumun emir ve direktifleri dahilinde çalıșması halinde doktorun elde edilen gelirin ücret sayılacağ belirlenmiştir. Özel sağ lık hastanelerde kuruma bağlı olarak, kurumun direktiflerine uyum sağlayarak, kurumun belirlemiş olduğu işe giriş çıkış saatleri içerisinde doktorun mesleğini icra etmesinden dolayı elde edilen gelir ücret olarak değerlendirilmesi ve kurum tarafından tevkif suretiyle vergilendirilerek kurumun bağlı olduğu vergi dairesine stopaj tutarının beyan edilerek sorumlu sıfatı (hekimin adına) beyan edilmesi gerekmektedir.

Serbest meslek kazancının tanımına yukarıda yer verilmiş olup her koşulda serbest meslek faaliyetlerinden elde edilen gelirlerin serbest meslek kazancı olduğu tanımlanmıştır. 16.02.2009 tarihinde 40 No'lu Vergi Usul Kanunu'nun sirkülerinde özel sağlık kurumlarında göre v alan doktorların gelirlerin mahiyeti belirlenmiş, doktorların işe başlama tebliğ, tebliğ üzerine düzenlenen yoklama fişi, mevcut ise kira sözleşmesi, özel sağlık kurumlarını işleten gerçek veya tüzel kişilerle doktorların arasında düzenlenen anlaşmalar dikkate alınarak;Doktorların, günlük çalışma saatlerinin belli bir süresini çalışmak üzere kiraladıkları muayenehanede kendi adına ve hesabına serbest mesleklerini icra etmeleri, uzmanlık faaliyetlerine ilişkin hastalarından alınan ödemelere istinaden serbest meslek makbuzu düzenlenmeleri koşulu ile dok torun elde ettikleri gelir serbest meslek kazancı sayılacağı belirlenmiştir.

Serbest meslek erbabı olması durumunda 4B kapsamında Bağ-Kur'lu olacak ve doktorun kurum tarafından yapılan ödemelere istinaden serbest meslek makbuzu düzenlenmesi gerekecektir.

Doktorların mesleki faaliyetlerine ilişkin yapılan ödemelerden \%20 oranında tevkifat yapılması gerekmektedir. Doktorun ilgili hesap döneminde 3'er aylık dönemlerinde elde edilen kazancı geçici beyanname ile beyan edilecek, söz konusu ödenen geçici vergilerin yıllık beyannameden mahsup işleminden sonra kalan tutar beyan edilir. 


\section{YÖNTEM}

Çalışmanın bu bölümünde serbest meslek mükellefiyeti tesis ettin özel sağlık kurumunda görev alan 3 mükellefin 2018 hesap döneminde beyan edilen gelir ve gider kalemlerine göre vergisel incelemeleri gerçekleştirilmiştir. Söz konusu mükelleflerin elde edilen gelir ve gider kalemleri baz alınarak 2018 hesap döneminde ödenmesi gereken vergi tutarları ve elde edilen net tutarlar tespit edilmiştir.

Özel sağ lık kurumunda serbest meslek tesis ettiren üç mükelleflerin 2018 hesap döneminde elde ettikleri kazançları baz alınarak söz konusu tutarların ücret geliri olması halinde vergisel incelemeleri gerçekleştirilmiş ve karşılaştırılmalı analiz yapılarak incelenmiştir. Her iki elde edilen gelir türleri karşılaştırılmış olup ödenmesi gereken vergi tutarları karşılaştırılarak vergisel yönden avantaj ve dezavavantajları tespit edilmiş tir.

2018 hesap döneminde serbest meslek mükellefiyeti tesis ettiren üç hekimin ücret geliri elde etmesi durumunda işveren maliyeti analizi gerçekleştirilmiş olup işverene sağladığı avantaj ve dezavantajları ele alınmıştır.

\section{BULGULAR}

Özel sağlık kurumunda serbest meslek erbabı olarak mesleğini icra eden ile ücretli olarak mesleğini icra eden hekime göre ver gisel yönden daha avantajlı olduğu tespit edilmiştir. Serbest meslek erbabı olarak mesleğini icra eden hekimin giderleri minimum seviyede olduğu halde ücretli göre daha az vergi yükümlülüğü bulunmaktadır. Ancak özel sağlık kurumunda serbest meslek erbabı ile ücretli olarak mesleğini icra eden hekime göre iş hukuku anlamında dezavantajları olacak olup serbest meslek faaliyetinde bulunması halinde iş̧̧i-işveren bağı olmayacak ve iş güvencesini kaybedecektir.

- Doktorun iş akdine son verilmesi halinde kıdem ve ihbar tazminatlarını alamayacaklardır.

- Doktor fazla mesaiye isabet ücretlerini elde edilemeyecektir.

- $\quad$ Analık izni, süt izni gibi izin sürelerini hak kazanamayacaklardır.

- İş kazası sonucu herhangi bir yasal başvuru ile tazminat hakkı olmayacaktır.

- Hekimin en az bir yıl çalışması halinde yıllık izin talep edemeyecek ve iş akdine son verilmesi halinde ise kullanılamayan yıllık izin ücretlerini talep edemeyeceklerdir.

Açıklamalar dahilinde anlaşılacağı üzere özel sağlık kurumu istediği zaman hekimin görevine iş akdine son verecek ve hukuksal tüm sorumluluklarından kurtulabilecektir. Öte yandan özel sağlık kurumuna hiçbir ek maliyete katlanmadan bu iş akdine son verebilecektir.

Öte yandan özel sağlık kurumunda serbest meslek mükellefiyeti tesis ettirirek üç hekimin ücret geliri elde etmesi yani hekimi işçi-işveren bağına bağı olarak ve emir talimatları doğrultusunda çalıştırması durumunda işveren ek bir maliyetine katlanması gerektiği tespit edilmiştir.

Özel sağlık kurumunda serbest meslek tesis ettiren üç mükellefin 2018 hesap döneminde gelir ve gider kalemleri dikkate alınarak gelir vergisi tutarları tabloda detayına yer verilmektedir. Söz konusu hekimlerin 2018 hesap döneminde elde ettikleri kazanç tutarlarının a ynı olduğu varsayımı altında ilgili tutarların ücret geliri olması halinde gelir vergisi tutarları hesaplanmıştır. Fark her iki elde edilen kazanç tutarları üzerinden hesaplanan gelir vergisi tutarlarını ifade etmektedir.

Tablo 1: Üç Serbest Meslek Mükellefin İşverene Tabii Olma Durumundaki 2018 Hesap Döneminde Karşılaştırılması

\begin{tabular}{|c|c|c|c|}
\hline & Mükellef (C) & Mükellef (B) & Mükellef (A) \\
\hline \multicolumn{4}{|c|}{ S.M. Mükellefi ile İşverene Tabii Olma Durumundaki Gelir Vergisi Tutarlarının Karşılaştırılması } \\
\hline Brüt Ücret & $1.266 .000,00$ & $1.132 .200,00$ & $750.000,00$ \\
\hline İşverene Tabi Gelir Vergisi & $420.790,52$ & $373.960,52$ & $240.190,52$ \\
\hline Gelir Vergisi (Serbest Meslek Mükellefi) & $203.752,29$ & $150.407,93$ & $150.000,00$ \\
\hline Fark & $217.038,23$ & $223.552,59$ & $90.190,52$ \\
\hline \multicolumn{4}{|l|}{ IŞVEREN MALIYETi } \\
\hline Brüt Ücret & $1.266 .000,00$ & $1.132 .200,00$ & 750.000 \\
\hline SSK İşveren & $28.311,84$ & $28.311,84$ & $28.311,84$ \\
\hline İşsizlik Işveren & $3.653,16$ & $3.653,16$ & $3.653,16$ \\
\hline Işveren Maliyet & $1.297 .964,88$ & $1.164 .164,88$ & $781.964,88$ \\
\hline
\end{tabular}

\section{SONUÇ VEÖNERILER}

Özel sağlık kurumunda serbest meslek olarak mesleklerini icra eden hekimlerin ücretli olarak mesleklerini icra eden hekimlere ile karşılaştıııldığında vergisel yönden avantajlı olduğu anlaşılmıştır. Burada vurgulanmak istenilen konu, serbest meslek erbabı olan doktorun iş güvencesinin olmaması nedeniyle özel sağlık kurumu karşısında daha güçlü durması için yapılacak olan sözleşmeler doktorun haklarını da güvence altına alan sözleşme olup tek taraflı bir sözleşme olmaması gerekmektedir. Hekim ile kurum arasında imzalanan iş sözleşmesi serbest meslek erbabı hekimin mağduriyetini gidermelidir. Sözleşmede tüm detaylar hakkediş tutarları, sabit ücretleri ve yasal hakları açıkça belirtilmelidir.

Serbest meslek erbabı olarak görev alan hekimlerin harcamalarıve gelirleri göz önüne alındığında kayıt dışı ekonominin engellenmesi adına hem de ücretli olarak mesleklerini icra eden hekimlerin bu alandaki mesleklerin kutsallı̆ı gereği ve geniş bir kitleye hitap etmesi pozitif ayrımcılığı göz önüne alındığında vergi yükümlülüklerini azaltmak adına vergi oranlarının değiştirilmesinin uygun olacağı anlaşımaktadır. Ayrıca özel sağlık kurumuna vergisel teşvikler getirilerek özel sağlık kurumunun maliyetleri indirgenerek kurumunda görev aldıkları hekimleri korumak adına ücretli olarak çalıştırılması hem kayıt dışı ekonominin azalmasına hem de doktorun iş güvencesinin sağlaması için teşvik uygulamaları yerinde olacaktır. 


\section{KAYNAKÇA}

Türkay i. (2016): "Serbest Meslek Kazançlarının Vergilendirilmesi”, Ankara: Seçkin Yayınları, 3. Baskı.

Akif, E. (1998). Kamu Maliyesi, Ankara, Savaş Yayınları.

Türk Tabipler Birliği. (2018). Özel Sağlık Sektöründe Çalışma ve Ücr etlendirme Biçimleri.

Koç, \& Kurt. (2007)

Sağlanmak, B. (2016): “Özel Sağlık Kuruluşlarında Çalışan Hekimlerin (Doktorlar, Diş Hekimleri ve Veteriner Hekimlerin) Vergilendirilmesi Yeri ve Önemi”, Vergi Dünyası, Kasım.

Bakmaz Z. (2011): "Serbest Meslek Faaliyetinde Bulunan Şahıs Şirketlerinin Vergilendirilmesinde Özellik Arz Eden Hususlar, Yaklaşım, Temmuz.

Başar M. (2012): “Gelir Vergisi”, Maliye Araştırma Merkezi Konferansları.

Armağan, R. (2006): “Gelir Vergisi’nde Ücret Gelirlerinin Vergilendirilmesi ve SosyoEkonomi Etkileri Üzerine Bir Değerlendirme”, Süleyman Demirel Üniversitesi, iiBF Dergisi, Cilt:11, Sayı:2, 323-347.

Gelir Vergisi Kanunu

Gündüz F. (2009): "Serbest Meslek Kazancının Beyanında Özellikli Konular" Yaklaşım, Mart.

Yılmaz K. (2005): "Ücretlerin Vergilendirilmesi”, Ankara: Ce-Ka Yayınları, Değiştirilmiş 2. Baskı.

Buyrukoğlu, S. \& Erasa İ. (2012): "Vergi Bilincinin Oluşmasında Mükellef Haklarının Yeri ve Önemi

Emen Ö. \& Hacı B. (2019). Birden Fazla İşverenden Ücret Alanlara Vergi Dairesi Kancası. Nazalı Gündem.

http://www.gib.gov.tr/ 